\title{
A SHORT OXYGEN EXPOSURE ENHANCES THE NEWBORN PULMONARY VASOCONSTRICTION RESPONSE IN MALE AND CAUSES THE OPPOSITE EFFECT IN FEMALE RATS
}

\author{
M. Enomoto ${ }^{1}$, E. Cubells ${ }^{2}$, J. Escobar ${ }^{3}$, M. Vento ${ }^{4}$, J. Belik $^{1}$ \\ ${ }^{1}$ Pediatrics, The Hospital for Sick Children, Toronto, ON, Canada, ${ }^{2}$ Division of Neonatology, ${ }^{3}$ Health \\ Research Institute, ${ }^{4}$ Division of Neonatology \& Health Research Institute, University and Polytechnic \\ Hospital La Fe, Valencia, Spain
}

Background and aim: Supplemental oxygen is often used to resuscitate newborns. The aim of this study is to examine the effect of a short oxygen exposure $\left(100 \% \mathrm{O}_{2}\right.$ for $\left.1 \mathrm{~h}\right)$ in male and female newborn $(<7$ days) rat lung, since sex is one of determinant factors in the prognosis of neonatal diseases.

Methods: Lungs were retrieved for $\mathrm{H}_{2} \mathrm{O}_{2}$ content and superoxide dismutase (SOD) activity measurements, and the intrapulmonary arteries were dissected for isometric evaluation of thromboxane $\mathrm{A}_{2}$ analog (U46619)induced force normalized to $\mathrm{KCl}$ stimulation. Air-treated rats served as controls.

Results: Oxygen exposure enhanced contraction of male, but not female pulmonary arteries. Catalase, a $\mathrm{H}_{2} \mathrm{O}_{2}$ scavenger, abolished the force-difference in females. Tiron, a superoxide scavenger, eliminated the force-difference in males. The $\mathrm{H}_{2} \mathrm{O}_{2}$ content and SOD activities were significantly increased in the $\mathrm{O}_{2}$-treated female, but not male lungs. A similar oxygen exposure had no effect on the contraction of older rats.

Conclusions: A short oxygen exposure in newborn, but not older rats induces reactive oxygen species generation that amount to a predominance of superoxide in males resulting in increased pulmonary arterial contraction. In contrast, the SOD activation in female lungs generates $\mathrm{H}_{2} \mathrm{O}_{2}$, resulting in reduced arterial contraction. This sex-difference may play a role in the increased morbidity/mortality of male newborn exposed to supplemental oxygen at birth.

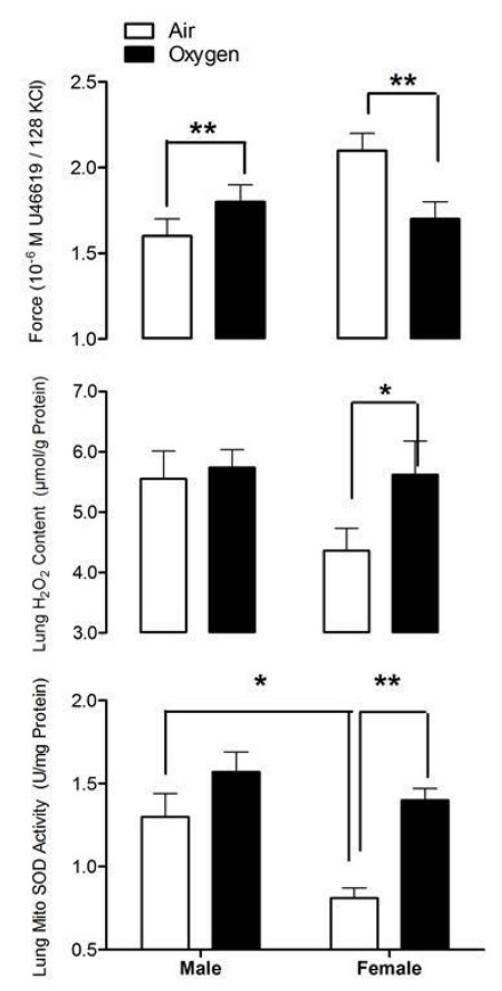

[FIgure] 